\title{
Case-based interprofessional learning for undergraduate healthcare professionals in the clinical setting
}

Jamal Nasir, Julie Goldie, Annabel Little: Department of Education, St. George’s University Hospitals NHS Foundation Trust, London, UK

Debasish Banerjee: Renal \& Transplantation Unit, St. George’s University Hospitals NHS Foundation Trust, London, UK

Scott Reeves: Centre for Health \& Social Care Research, Kingston University \& St. George’s, University of London, London, UK

\section{Introduction}

The importance and benefits of interprofessional learning (IPL) for healthcare professionals has been recently highlighted in UK healthcare policy documents (e.g. Department of Health, 2015; NHS, 2014) and is increasingly expected to be introduced into the undergraduate curriculum by course accreditation bodies for medicine (Mahler et al., 2015), pharmacy, and other healthcare professions.

Research into IPL has found it can lead to positive outcomes for patients (WHO, 2010). For example, through improved collaboration resulting from IPL, patients have reported being more satisfied because of less time spent in hospital, with reduced readmission, mortality, and morbidity rates resulting in improved quality of care, costs, and error rates (Institute of Medicine, 2015).

The changing face of healthcare along with the emergence of new healthcare professions, such as physician associates, as well as an increasing expectation for interprofessional collaboration, necessitates specific training of undergraduate healthcare professionals (Frenk et al., 2010). IPL is therefore increasingly being introduced into undergraduate courses covering healthcare sciences, including nursing, pharmacy and medicine. However, it is sometimes classroom-based with only limited opportunities for its use in clinical settings.

In response to student demand, we wanted to undertake this in a clinical setting with real patients. Our aim was to enable students from different healthcare professional backgrounds to gain a better understanding of each other's roles, improve students' professional competence and seek better outcomes for patients.

\section{Background}

All undergraduate healthcare professional students on placement at St. George's University Hospitals NHS Foundation Trust were invited to attend an IPL session. Invitations were sent out to students through their course organisers and clinical teachers and an online booking system was set up. The students were also individually recruited by visiting the wards on a weekly basis. Students were allocated a slot to ensure a minimum of two different healthcare professions were represented in each session in order to qualify as an IPL session.

Course materials were designed in line with published guidance (Cross, Spencer, \& Hills, 2014; Lindqvist, Duncan, Shepstone, Watts, \& Pearce, 2005). Two cases were written ('patient management' or 'discharge planning') with the aim of applying them to any patient on the ward, focusing specifically on the roles of different healthcare professionals in managing the patient before, during and after admission to hospital. Six wards covering different clinical specialties (cardiac, respiratory, oncology/haematology, renal transplant, gastrointestinal, endocrine/diabetes) were selected as suitable areas for weekly IPL sessions to be delivered.

Students were asked to take part in collective history taking from a patient at the bedside. They were encouraged to think about the roles of the different healthcare professions in taking care of the patient. Students were then asked to summarise the history taking, and discuss the roles of different healthcare professionals in the context of the patient's illness whilst in hospital and also during and following their discharge and encouraged to think in particular about the changing face of healthcare delivery and the roles of new or highly specialised professions like physician associates, dieticians, psychologists, and speech and language therapists, bearing in mind their unique aims and shared goals. 


\section{Methods}

This study adopted a quasi-experimental post-intervention study design to evaluate student perceptions about their IPL experience. A formative evaluation of this IPL experience was undertaken, using Kirkpatrick's evaluation model (Kirkpatrick, 1994), to gather information about whether or not students had any previous experience of IPL, to learn about their perceptions of the session we offered, how (if at all) it would influence their future practice and to elicit further suggestions.

\section{Data collection}

All students who participated in this IPL experience were invited to complete a survey to evaluate the session, assessing attitudes - relating to level 2 of Kirkpatrick's model (Kirkpatrick, 1994)-as well as impact of the session on behaviours and practice, including interprofessional communication, learning and interaction. We developed a series of closed (see Figure 1) and open-ended questions (see Table 1). The questions were developed from the published literature (Parsell \& Bligh, 1999; Pollard, Rickaby, \& Miers, 2008).

\section{Data analysis}

All the data from the survey were entered into an Excel spreadsheet. Numeric data from the closed questions were analysed using descriptive statistics and a content analysis was employed for the open-ended questions.

\section{Ethical considerations}

Permission for this study was obtained through St. George's Joint Research and Enterprise Office. Patients were consented ahead of each session by the facilitator and again at the beginning of the session by the students. The patients were informed about our main goal of fostering interprofessional teamwork for their benefit - their views were sought at the beginning and end of the session.

\section{Results}

Three hundred and twenty-nine students from different healthcare professional backgrounds [nursing $(n=143)$, pharmacy $(n=139)$, medicine $(i=28)$, physician associate $(n=8)$, physiotherapy $(n=7)$, midwifery $(n=2)$, occupational therapy $(n=1)$, speech and language therapy $(n=1)$ ] attended an IPL session over an 8-month period. Overall, a mix of junior and senior students participated in the sessions. The nursing students included a mixture of new and more experienced students, some with previous degree level qualifications, but for the other professions including physician associates which is a postgraduate course, the students were mostly closer to the end of their course. The majority of the pharmacy students were third year students, with some 4th year students.

Forty per cent of the students reported experiencing case-based IPL for the first time. Of the remaining $60 \%$ who reported having previous experience of interprofessional case-based learning, for the majority of these students it did not involve a real patient on a medical ward to the best of our knowledge. Between ninety-three and ninety-nine per cent of students overall, strongly agreed or agreed with a series of statements supporting the benefits of IPL (see Figure 1). Moreover, $70 \%$ of students said they would do things differently as a result of the session, including students who had previously attended IPL training and those who had not.

The majority of the responses to the open-ended questions were overwhelmingly positive. The three main themes related to how much the students enjoyed the sessions, how much they enjoyed working with other professionals and wanting a wider cross section of healthcare disciplines represented per session. Asked about how they would change their future practice, almost half of the students (41\%) said they would find out more about or work more closely with multidisciplinary teams and many of these also advocated a more patient centred approach whilst also referring for a need to improve 'communication' and 'confidence' when dealing with other professionals as well as patients (see Table 1). When asked about suggestions for improving the session, almost half of the respondents offered no comment (45\%), with the remainder providing mainly positive or constructive feedback (Table 1). The most popular suggestion was to involve more healthcare professions; approximately a quarter of the students (24\%) mentioned this with many requesting more medical students.

\section{Discussion}

We have developed and delivered student led case-based IPL sessions on medical wards to 329 undergraduate students, representing different healthcare professions, over an 8-month period in the current academic year. We have shown it is feasible to successfully deliver small group teaching (typically involving between 3 and 6 students per 
session) to a large number of students with just two facilitators over the course of an academic year.

Student evaluations of our sessions were overwhelming supportive, even for students who had previously experienced IPL with the vast majority of students overall indicating they would change their future practice. Clearly, this is something that needs to be explored further in future, by conducting follow-up interviews on focus groups with students and facilitators to generate data on whether as a result of the sessions there has been any long term change in the students views or behaviours regarding the way they interact with other health-care professions or how they interact with patients.

We developed a generic ('patient management') and a more specific case ('discharge planning') and although this did not appear to affect student feedback, further changes to consider for the future would be to set specific scenarios with specific tasks or perhaps organise a full-day session or organise more than one session to take account of the student feedback.

The majority of our students were nursing (43\%) or pharmacy $(42 \%)$ undergraduates. Our sessions were not compulsory, except for the pharmacy students. Attendance was made mandatory for these students, but their overall feedback was still strongly positive partly owing to the fact they had had limited learning opportunities on the ward. In order to attract more varied students, however, integrating the sessions into the teaching programme and making them compulsory is a possibility to consider for the future. In the case of medical students, IPL could be introduced into their core-competencies such as the mini Clinical Evaluation Exercise. Perhaps our current format of letting students be in charge of booking a session at a time that suits them might help facilitate this.

Although we managed to deliver the sessions to a large number of students, there was a feeling of a lack of awareness of the sessions despite our best efforts, so for future studies we recommend adding this information in the course handbooks. Implementing these changes could contribute towards overcoming factors influencing IPL sustainability. A recent review identified 1,570 articles relating to IPL barriers, but only 18 on IPL enablers (Lawlis, Anson, \& Greenfield, 2014) although some factors such as funding, were seen as both enablers and barriers. We support the notion of an IPL champion (as reported in the review) working across the different stakeholder boundaries to overcome timetabling, funding, staffing and other barriers such as lack of support from the individual professions. Finally, we aim to work with other institutes to expand this study across other sites and establish robust methods for its optimal delivery, evaluation and sustainability in the long term and to assess its impact on patients.

\section{Acknowledgements}

Thanks to Carole Beighton for her valuable contribution to the project, the ward managers, nurses, practice educators, course leads, administrative staff, lead consultants, and especially the patients for their help and cooperation. We would also like to thank John Hammond and Deborah Harding for evaluating and giving feedback on our scenarios and Carol Dicken and Shereen Nabhani-Gebara for sitting in the sessions and providing additional feedback. John Hammond also provided guidance for the evaluation questionnaire. Finally, we would like to thank Fiona Graham for statistical support.

\section{Declaration of interest}

The authors report no conflicts of interest. The authors alone are responsible for the content and writing of this article.

\section{Funding}

We would like to thank Health Education England South London (HEE-SL, grant no. ST95) for generously funding this work.

\section{References}

Cross, M., Spencer, J., \& Hills, J. (2014) Guide to developing simulated interprofessional learning activities, faculty of health, UTAS. Retrieved from http://www.utas.edu.au/_ data/assets/pdf_file/0020/528014/eGuide-to-developing- 
Department of Health. (2015). Delivering high quality, effective, compassionate care: Developing the right people with the right skills and the right values. Retrieved from https://www.gov.uk/government/uploads/system/uploads/attachment_data/file/411200/HEE_Mandate.pdf Frenk, J., Chen, L., Bhutta, Z. A., Cohen, J., Crisp, N., Evans, E. Zurayk, H. (2010). Health professionals for a new century: Transforming education to strengthen health systems in an interdependent world. The Lancet, 376, 19231958. doi:10.1016/S0140-6736(10)61854-5

Institute of Medicine. (2015). Measuring the impact of interprofessional education on collaborative practice and patient outcomes. Washington, DC: The National Academies Press.

Kirkpatrick, D. L. (1994). Evaluating training programs. San Francisco, CA: Berrett-Koehler Publishers, Inc.

Lawlis, T. R., Anson, J., \& Greenfield, D. (2014). Barriers and enablers that influence sustainable interprofessional education: A literature review. Journal of Interprofessional Care, 28(4), 305-310. doi:10.3109/13561820.2014.895977

Lindqvist, S., Duncan, A., Shepstone, L., Watts, F., \& Pearce, S. (2005). Case-based learning in cross-professional groups - the development of a pre-registration interprofessional learning programme. Journal of Interprofessional Care, 19(5), 509-520. doi:10.1080/13561820500126854

Mahler, C., Berger, S. J., Karstens, S., Campbell, S., Roos, M., \& Szecsenyi, J. (2015). Re-profiling today's health care curricula for tomorrow's workforce: Establishing an interprofessional degree in Germany. Journal of Interprofessional Care, 29(4), 386-388. doi:10.3109/13561820.2014.979980

NHS. (2014). Five year forward view. Retrieved from https://www.england.nhs.uk/wpcontent/uploads/2014/10/5yfv-web.pdf

Parsell, G., \& Bligh, J. (1999). The development of a questionnaire to assess the readiness of health care students for interprofessional learning (RIPLS). Medical Education, 33, 95-100. doi:10.1046/j.1365-2923.1999.00298.x

Pollard, K., Rickaby, C., \& Miers, M. (2008) Evaluating student learning in an interprofessional curriculum: The relevance of prequalifying inter- professional education for future professional practice (Project Report). Health Sciences and Practice, The Higher Education Academy. Retrieved from http://eprints.uwe.ac.uk/7240/1/kpollard.pdf WHO. (2010). Framework for action on interprofessional education \& collaborative practice. Geneva: World Health Organization. Retrieved from http://www.who.int/hrh/resources/framework_action/en/index.html 


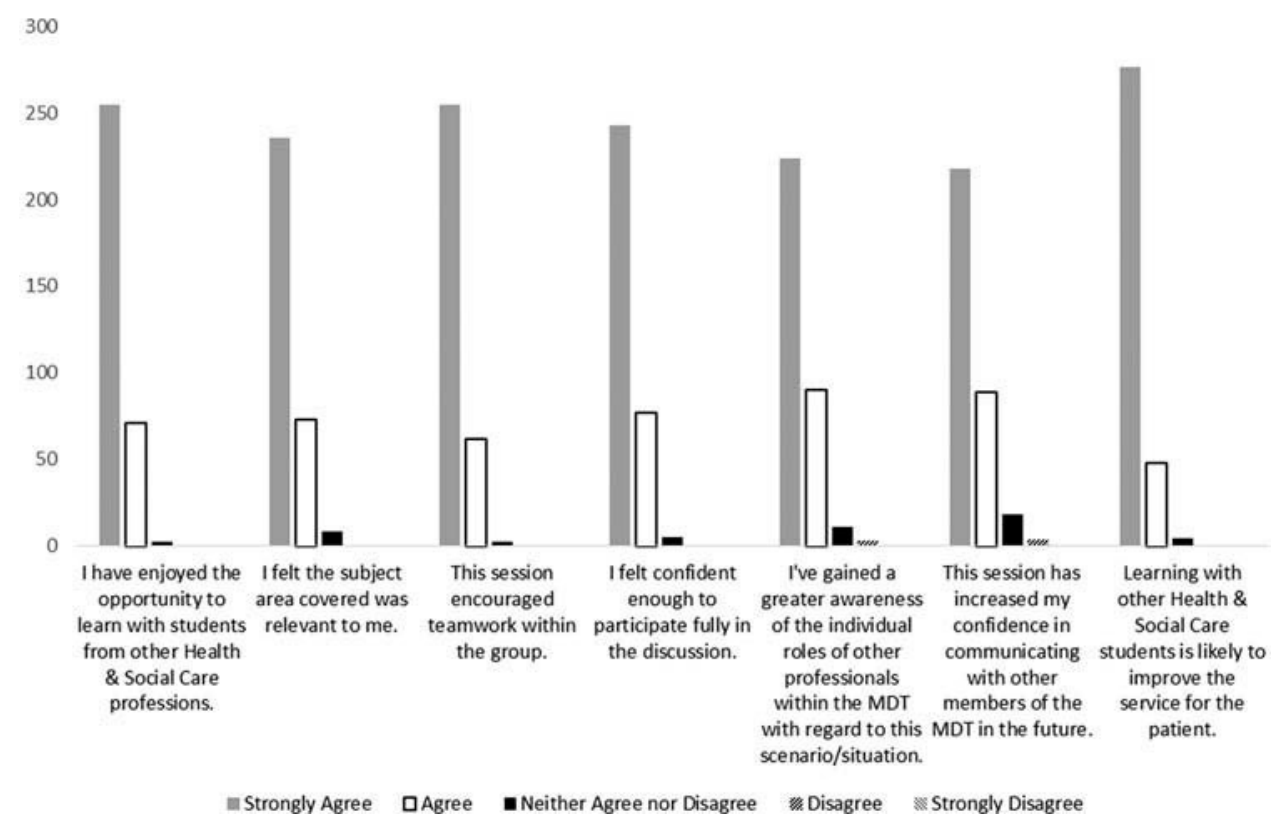

Figure 1.

Evaluation of case-based learning in the clinical setting. Three hundred and twenty-nine students who attended the session were surveyed to record their attitudes on interprofessional communication, learning and interaction, and future practice. The number of students is indicated on the $y$-axis.

\section{Table 1. Students' feedback on the session.}

Do you intend to do anything differently as a result of today's session? Please describe:

- Think about everyone's different and overlapping roles within the team (Medicine).

- Learn more about other professions and their specific roles in patient's care (Nursing).

- Liaise more with other healthcare professionals on the ward (Pharmacy).

- Tell my colleagues to sign up to the programme (Pharmacy).

- Definitely look out for and take part in other events like this (Pharmacy).

- It was very good, enjoyed it very much (Pharmacy).

- I engaged with other healthcare professions; gave me an insight at what nurse's do which was very interesting and eye opening (Pharmacy).

\section{Do you have any suggestions for improvements to this session?}

- The session was well run and administered and stimulated a lot of thought about interprofessional collaboration (Medicine).

- Really enjoyed the session, loved interacting with the patient as well as other healthcare professions (Pharmacy).

- No suggestions. There should be more opportunities for this kind of learning (Medicine).

- It was really interesting and should be continued (Nursing).

- Make it compulsory for all healthcare professionals (Pharmacy).

- If possible more ward round as the experience with students from different health courses is interesting. Maybe, shadow other practitioners e.g. dieticians and physiotherapist if students are limited (Nursing).

- Try to have at least one med student if possible as they are a big part of the team (Nursing).

- More students from different professions so we can learn more about their roles (Nursing). 